\title{
Exome first approach to reduce diagnostic costs and time - retrospective analysis of 111 individuals with rare neurodevelopmental disorders
}

Julia Klau', Rami Abou Jamra1, Maximilian Radtke, Henry Oppermann¹, Johannes R. Lemke $^{1,2}$, Skadi Beblo ${ }^{2, *}$, Bernt Popp ${ }^{1, *}$

${ }^{1}$ Institute of Human Genetics, University of Leipzig Medical Center, Leipzig, Germany

${ }^{2}$ Center for Rare Diseases, University of Leipzig Medical Center, Leipzig, Germany

* These authors contributed equally to this work 
medRxiv preprint doi: https://doi.org/10.1101/2021.07.23.21258974; this version posted July 24, 2021. The copyright holder for this preprint (which was not certified by peer review) is the author/funder, who has granted medRxiv a license to display the preprint in perpetuity.

It is made available under a CC-BY-NC 4.0 International license .

\section{ABSTRACT}

This single center study aims to determine the time, diagnostic procedure and cost saving potential of early exome sequencing in a cohort of 111 individuals with genetically confirmed neurodevelopmental disorders.

We retrospectively collected data regarding diagnostic time points and procedures from the individuals' medical histories and developed criteria for classifying diagnostic procedures in terms of requirement, followed by a cost allocation. The genetic variants of all individuals were reevaluated according to ACMG recommendations and considering the individuals' phenotype.

Individuals who developed first symptoms of their underlying genetic disorder when Next Generation Sequencing (NGS) diagnostics were already available received a diagnosis significantly faster than individuals with first symptoms before this cutoff. The largest amount of potentially dispensable diagnostics was found in genetic, metabolic, and cranial magnetic resonance imaging examinations. Out of 407 performed genetic examinations, $296(72.7 \%)$ were classified as potentially dispensable. The same applied to $36(27.9 \%)$ of 129 cranial magnetic resonance imaging and $111(31.8 \%)$ of 349 metabolic examinations. Dispensable genetic examinations accounted $302,947.07 €(90.2 \%)$ of the total $335,837.49 €$ in potentially savable costs in this cohort. The remaining $32,890.42 €(9.8 \%)$ are related to non-required metabolic and cranial magnetic resonance imaging diagnostics. On average, the total potentially savable costs in our study amount to $€ 3,025.56$ per individual.

Cost savings by first tier exome sequencing lie primarily in genetic, metabolic, and cMRI testing in this German cohort, underscoring the utility of performing exome sequencing at the beginning of the diagnostic pathway and the potential for saving diagnostic costs and time.

KEYWORDS: diagnostic exome sequencing, neurodevelopmental disorders, epilepsy, diagnostic costs, cost reduction 
medRxiv preprint doi: https://doi.org/10.1101/2021.07.23.21258974; this version posted July 24, 2021. The copyright holder for this preprint (which was not certified by peer review) is the author/funder, who has granted medRxiv a license to display the preprint in perpetuity.

It is made available under a CC-BY-NC 4.0 International license .

\section{INTRODUCTION}

Neurodevelopmental disorders (NDD) and epilepsy are frequent causes for medical presentations and diagnostics. ${ }^{1,2}$ NDD affect approximately $3 \%$ of children worldwide while about 1 in 150 children develops epilepsy in the first 10 years of life., ${ }^{3,4}$ Both conditions comprise very heterogeneous etiologies that include several hundred rare genetic disorders. ${ }^{5-8}$

Establishing a diagnosis involves coordinated interplay between pediatricians, neurologists, geneticists and other physicians in centers for rare diseases. This complex process is often highly time consuming, requires great effort through a huge amount of diagnostic procedures and immensely burdens affected families..$^{9-12}$ The associated diagnostic costs and risks are considerable, underscoring the scope of this "diagnostic odyssey" and the load on the health care system. ${ }^{13}$ The impact of a conclusive genetic diagnosis for affected individuals and families has been the subject of several studies and demonstrates the importance of developing guidance for an effective diagnostic pathway. ${ }^{9,14-16}$

Genetic diagnostics have traditionally been initiated at a relatively late stage in the diagnostic pathway and were often performed in a stepwise manner. ${ }^{17,18}$ Since its introduction, highthroughput sequencing has proven to be an effective, rapid but cost-intensive method in genetic diagnostics ${ }^{19}$ and has evolved from a research method to a routine diagnostic tool. ${ }^{20}$ Next Generation Sequencing (NGS) outperforms traditional genetic diagnostics, as it can achieve a diagnostic yield between $30 \%$ and $47 \%$ in NDD and epilepsy cohorts combined with speed-up through a single test. ${ }^{18,21-24}$ Thus, the question remains ${ }^{25}$ whether first-line initiation of exome sequencing (ES) could save costs and time, reduce the risks associated with thereby obsolete extensive or even invasive diagnostic procedures, and allow families to make earlier reproductive decisions.

To address these questions, we designed a retrospective single-center study focusing on diagnostic procedures and time durations in 111 individuals with NDD and/or epilepsy who obtained a molecular diagnosis through NGS methods. We wanted to determine the extent to which NGS diagnostics influenced the duration of the diagnostic odyssey and to assess the 
medRxiv preprint doi: https://doi.org/10.1101/2021.07.23.21258974; this version posted July 24, 2021. The copyright holder for this preprint

number of diagnostic interventions that might have not been required retrospectively if ES had been implemented earlier in this cohort.

\section{MATERIALS AND METHODS}

\section{Ethics Approval}

The project was approved by the ethic committee of the University of Leipzig, Germany (224/16-ek and 402/16-ek) and was conducted in concordance to the declaration of Helsinki. Individuals or their parents or legal guardians consented to genetic testing.

\section{Study design and patient selection}

We retrospectively selected 111 individuals with pediatric-onset NDD and/ or epilepsy from a diagnostic cohort of 2128 cases based on a series of filtering and quality control steps. All individuals had received a molecular diagnosis in this regard using NGS methods at the Institute of Human Genetics at Leipzig University Medical Center (UKL), a tertiary care centre in Germany. The participants received their diagnoses between 2017-04-04 and 2020-08-03. Further details on inclusion and exclusion criteria are provided in Figure $1 \mathrm{~A}$. These criteria are intended to ensure that physician letters were available for all individuals to collect data on diagnostic procedures as well as time points of interest. Therefore, we excluded individuals who received no clinical assessments at UKL and those born before the year 2000. To assure that only individuals with sufficiently clarified genetic diagnoses were included, we excluded cases where only variants of uncertain significance (VUS) had been reported in the initial diagnostic report. This resulted in a list of 112 individuals for which we collected clinical data. After systematic variant reevaluation in the course of this project, we excluded one individual where the previously reported variant does not sufficiently explain the severity of the case (Ind076; for further details see Supplemental File S3).

\section{Clinical data collection and classification}


medRxiv preprint doi: https://doi.org/10.1101/2021.07.23.21258974; this version posted July 24, 2021. The copyright holder for this preprint

The internal patient information systems of the UKL were used to curate genetic and clinical information from the individuals' medical history. We collected data on all diagnostic measures i.e. genetic analyses, cranial magnetic resonance imaging (cMRI), metabolic diagnostics (defined as analyses of parameters in a blood, urine or liquor sample, such as organic acids, amino acid profiles, acylcarnitines, etc.), other laboratory diagnostics, lumbar punctures, other medical imaging than cMRI (including sonographic, endoscopic, X-ray and computer tomography examinations), electrocardiograms (ECG), electroencephalograms (EEG), electrophysiology, function tests (including spirometry, polysomnography and cardiorespirogram examinations) and conciliar examinations. Metabolic parameters examined in cerebrospinal fluid samples were assigned to metabolic diagnostics. The lumbar puncture itself and the associated laboratory tests concerning, for example, inflammatory parameters are included in the lumbar puncture category. For details on the specific types of the respective diagnostic procedures, see Supplemental File $S 2^{26}$ (sheet "costs"). We also included hospitalisations and counted the amount of inpatient overnight stays. For laboratory tests other than metabolic diagnostics, we only recorded whether they were performed at least once due to the amount of single data points with neglectable overall costs. We concentrated on the diagnostics performed at UKL excluding additional examinations potentially performed at other medical institutions. This approach is in-line with previous studies $^{27}$ and served to ensure a uniform approach because, especially in the case of individuals with a longer medical history at other hospitals, our access to physician letters was restricted. However, we included data on cMRI and genetic examinations performed in other medical institutions, because these information were consistently transmitted to the UKL. Our data collection involved all procedures performed from birth to the report of the final molecular diagnosis. We classified each diagnostic entry according to its requirement considering the individual medical history and the exact circumstances of each specific situation based on assessment by pediatricians experienced with rare diseases. Many diagnostic interventions were regarded as indispensable, especially for critically ill individuals or when warning signs like a reduced general condition, developmental regression, and new 
medRxiv preprint doi: https://doi.org/10.1101/2021.07.23.21258974; this version posted July 24, 2021. The copyright holder for this preprint

onset seizures were present. Our classification system was divided into three parts and contains the categories "not required", "required" and "ambiguous". All genetic investigations were classified as dispensable, except for the final NGS-based investigations leading to the diagnosis and their subsequent validation by Sanger, MLPA, and/ or q/RT-PCR. The curated classification criteria for all procedures are provided in Supplemental File $\mathrm{S2}^{26}$ (sheet "criteria").

\section{Diagnostic time data collection}

We recorded diagnostic time points for each individual based on the structured diagnostic pathway as depicted schematically in Figure 1B. Data for the following time points were collected: occurrence of first symptoms associated with the genetic phenotype (t1), initial diagnostics related to the underlying genetic disease (t2), first consideration of a genetic differential diagnosis (t3), initiation of first genetic diagnostics (t4), enrollment of the NGSbased examination that lead to the final diagnosis (t5) and the corresponding diagnosis report date (t6).

\section{Costs}

Subsequent to the clinical data collection, we determined associated diagnostic costs using a retrospective bottom-up approach. This refers to our concept of inferring the total cost to the health care system from determining the cost of individual procedures. We focused on direct costs incurred solely due to diagnostic procedures. Other direct medical costs as well as indirect costs were not considered. The cost calculation is based on the "Gebührenordnung für Ärzte" (GOÄ), which determines the billing of medical costs in the outpatient sector in Germany. Even though many diagnostic measures performed on the individuals in our cohort occurred in a hospital setting, we nevertheless calculated them on the basis of the GOÄ. In Germany, costs incurred during hospitalizations are billed as flat-rate payments via Diagnosis Related Groups (DRGs), which does not allow conclusions to be drawn about particular diagnostic costs. ${ }^{3}$ Therefore, we also did not include the costs of hospitalization in our cost 
calculations to avoid duplications. We focused the cost analysis on the three categories with the largest amounts of non-required procedures, which were genetic diagnostics, cMRI, and metabolic diagnostic costs. Our estimated costs for gene panel sequencing, trio ES and single ES were fixed to $3461.45 €$ per examination based on the GOÄ cost system in September 2020 including accounting of the nucleic acids isolation from the blood sample, sequencing and scientific evaluation and report. This cost level is consistent with estimated costs of NGS-based diagnostics in other studies. Schwarze et al. ${ }^{28}$ report a range of costs for ES between $555 \$$ and $5,169 \$$ (inflated value in $€: 507,79 €-4729,30 €$ ); Vrijenhoek et al. ${ }^{22}$ state 3,600€ (inflated value: 3,693.27€) for ES consistent with our costs. We inflated the costs for comparative purposes using a web inflation tool (https://www.inflationtool.com) and converted them subsequently to Euro using corresponding daily exchange rates from Bloomberg L.P. on 2021-05-06 (for conversion and inflation calculation of costs see Supplementary Table S1). A specific diagnostic costs summary is available in Supplementary File S2 ${ }^{26}$ (sheet "costs").

\section{Genetic Analyses and Variants Reevaluation}

All individuals were diagnosed by NGS-based examinations such as gene panel, single ES or trio ES. To increase sample size, we included individuals diagnosed by gene panel examinations in our cohort because we assumed the identified variants were definitively diagnostic and would have been detected by exome sequencing as well. ${ }^{23}$ Only those individuals with variants classified as pathogenic or likely pathogenic and considered to fully cause the phenotype were selected for this study. We performed a reevaluation of all detected variants according to the updated guidelines provided by the American College of Medical Genetics and Genomics (ACMG) $)^{29}$ to standardize and update all variant pathogenicity assessments. For consistent variant nomenclature and standardized evaluation, web resources like ClinVar, Varsome, Decipher, Mutalyzer, gnomAD, ClinGen Pathogenicity Calculator and AutoPVS1, were used. We ensured that all variants reported here were submitted to ClinVar (see Supplementary File $S 3^{26}$ for ClinVar IDs). 


\section{Statistical analysis and Data Plotting}

We analysed and graphically processed the data compiled in Excel (Microsoft Corporation, Redmond, Washington, USA) using R language (Version 4.0.5) from within RStudio (Version 1.4). Because of its infrequent application, the diagnostic entries that were marked in the "ambiguous" category were assigned to the "required" category for our statistical analysis following a conservative evaluation approach. In order to make comparisons of diagnostic times intervals we subdivided the cohort. This division was based on the onset time of first symptoms concerning the genetic phenotype before and after the introduction of NGS-based diagnostics. This cut-off was set to April 1, 2016, the date since when NGS based diagnostics where broadly applied at our Institute of Human Genetics in Leipzig. We used two sided Wilcoxon signed-rank test as implemented in $R$ to calculate $p$-values for differences between groups. 
medRxiv preprint doi: https://doi.org/10.1101/2021.07.23.21258974; this version posted July 24, 2021. The copyright holder for this preprint (which was not certified by peer review) is the author/funder, who has granted medRxiv a license to display the preprint in perpetuity. It is made available under a CC-BY-NC 4.0 International license .

\section{RESULTS}

\section{Cohort demographics}

Of the 111 individuals included, 49 (44.1\%) were female and 62 (55.8\%) were male (ratio: 1:1.26). Due to the inclusion criteria described earlier (Figure 1A), all individuals enrolled were under 20 years of age at the time of diagnosis. Details of the sex-specific age distribution are provided in Figure 2A. Initial clinical diagnosis was NDD in $69(62.1 \%)$ of individuals, epilepsy in 10 (9\%), and a combined occurrence of both in 32 (28.8\%) (Figure 2B). In 10 individuals with isolated epilepsy the seizure onsets and genetic diagnoses occurred in a very young age, or no medical records were available for the time after genetic diagnosis. We examined further medical letters for possible later onsets of NDD, but no evidence for it was found. Thus, it cannot be excluded that NDD could still develop in these individuals later in life. The onset of the first symptoms associated with the underlying genetic disease developed at a median age of 6.2 months (range: 0 - 156.6; standard deviation (SD): 20.5) in the individuals. Out of 111 individuals 22 individuals (19.8\%) were already symptomatic regarding the molecular diagnosis on their day of birth and 50 individuals $(45 \%)$ showed symptoms in their first year of life; another 39 individuals (35.1\%) became symptomatic in their second year of life or later. A compilation of anonymized individual data is provided in Supplemental File $\mathrm{S}^{26}$.

\section{Genetic diagnostics}

By study design all 111 individuals received their molecular diagnosis by NGS-based genetic diagnostics. Four individuals (3.6\%) received an in-house custom-design panel targeting genes associated with epilepsy (“Epi-panel”, 122 genes). TruSight One v1 Panel (Illumina, Inc., San Diego, CA) was performed in 68 individuals (61.3\%) which includes 4,811 genes associated with human disease. Whole exome sequencing (WES) targeting all coding genes was performed in 38 individuals (34.2\%) using either a BGI Exome capture 59M kit (ten individuals; BGI, Shenzhen, China), SureSelect Human All Exon V6 (four individuals; Agilent Technologies, Santa Clara, CA, USA) or a TWIST Human Core Exome Kit (25 individuals; 
medRxiv preprint doi: https://doi.org/10.1101/2021.07.23.21258974; this version posted July 24, 2021. The copyright holder for this preprint

TWIST Bioscience, San Francisco, CA, USA) target design. For all included individuals, the genomic regions targeted by the respective enrichment design had an average coverage of $\geq$ 100 reads and $\geq 95 \%$ were covered by $\geq 10$ reads.

\section{Variant characteristics}

In 111 individuals, a total of 127 variants was reported through NGS-based diagnostics. The majority of $87(68.5 \%)$ variants were single-nucleotide variants (SNV), with the remainder composed of 15 (11.8\%) copy number variants affecting multiple genes (Large CNV), 13 $(10.2 \%)$ insertion/deletion variants (indel), ten (7.9\%) copy number variation whose alteration affects a single gene and involves several exons (Small CNV), and two complex events (1.6\%) summarized as "other" (Figure $2 \mathrm{C}$ ). These comprise an unbalanced translocation identified through coverage-based CNV analysis and subsequently confirmed by karyotyping and FISH and a deletion-insertion event in in MECP2 (Variant ID: CNV017 and SNV008; Supplemental File $S 3^{26}$ ). Of these 127 variants, 111 variant combinations represented as causative for the phenotypes of NDD/epilepsy in the individuals, whereas the other genetic alterations were related to other concerns or were incidental findings. The origin of most NDD/epilepsy-related variants was recorded as sporadic and de novo in 55 cases (49.5\%). The inheritance of eleven variants $(9.9 \%)$ was recessive and homozygous, ten $(9 \%)$ were dominant and inherited, another seven (6.3\%) variants combinations represented as recessive compound heterozygous variants, six (5.4\%) were X-linked recessive and two $(1.8 \%)$ were postzygotic. For 20 variants $(18 \%)$ no segregation was performed in the parents (Figure 2D). A detailed compilation of all identified variants is provided in Supplementary File $\mathrm{S}^{26}$.

\section{Variants Reevaluation}

Reevaluation resulted in downgrading of one variant previously reported as pathogenic and exclusion of one individual from subsequent analyses (Ind076; Supplemental File S3 ${ }^{26}$ ) leaving 111 individuals for our final cohort. The variant is a microdeletion (CNV_013) 
medRxiv preprint doi: https://doi.org/10.1101/2021.07.23.21258974; this version posted July 24, 2021. The copyright holder for this preprint

identified in Ind076 which does not adequately explain the highly disabled individual's phenotype in its severity. This individual deceased on the fourth day of life after uncontrollable seizures and severe asphyxia. The microdeletion identified, which includes SIN3A among others, is associated with milder disease cases. ${ }^{30}$ Because of the challenging assessability of this case due to the early death of the individual, we decided to exclude this case from our calculations, as we cannot fully clarify it. After reassessment of all variants formerly classified as (likely) pathogenic, 106 out of 111 phenotype-related variants remained in those assessment categories (Supplemental File $S 3^{26}$ ). Five variants had to be downgraded to VUS (Table 1). This can be explained inter alia by the change in recommendations regarding the PM2 criterion. A ClinGen ${ }^{31}$ recommendation to modify the strength of the PM2 criterion "Absent from controls, or at extremely low frequency if recessive, in Exome Sequencing Project, 1000Genomes Project, or Exome Aggregation Consortium"29 resulted in a downgrade from moderate to supportive. The PS2 criterion was betimes judged to be too strong in some but can only be assessed with strength moderate due to unspecific phenotype in most NDD entities and lack of data on the occurrence of this variant in other individuals. For further verification, RT-PCR would have been necessary for Ind069 to confirm the splice effect of the de novo variant c.4581+18A>G in SCN1A. Because these five variants were estimated to be very plausible with the phenotype despite their classification as VUS, we nevertheless considered these cases resolved ("hot VUS") and retained these individuals in the cohort. Further investigation and more information on other individuals with the same variants will prospectively help to improve the assessment of these cases in the future.

The re-evaluation of a SMAD4 duplication initially reported as incidental finding in Ind012 (Supplemental File $\mathrm{S3}^{26}$, Supplemental Figure $\mathrm{S} 1$ and $\mathrm{S} 2$ ) showed that this was a retrotransposition event rather than a true genomic duplication of exons 2-3 and 5-12 as initially assumed. Alterations in SMAD4 gene can cause the juvenile polyposis syndrome. ${ }^{32}$ The identification of the SMAD4 variant as a retrotransposition removes the need for preventive examinations regarding polyps in the gastrointestinal system of the individual and 
medRxiv preprint doi: https://doi.org/10.1101/2021.07.23.21258974; this version posted July 24, 2021. The copyright holder for this preprint

its family. A correction report was submitted to the affected family based on the reassessment in our study.

\section{Time periods in the diagnostic pathway}

The total diagnostic time (first symptoms to final diagnosis) was split into subintervals (Interval 1-5; Figure 1B) to allow granular analysis of the diagnostic trajectory. The median duration between onset of symptoms associated with the underlying genetic disease and the final genetics report establishing the diagnosis was 34.1 months (range: $0.6-210.5$; SD: 57.4). A median of 64.5 days (range: 8 - 395; SD: 60.8 ) passed between the initiation of NGS-based diagnostics leading to molecular diagnosis and the report of the molecular diagnosis.

We compared the length of subintervals in individuals with first symptoms before $(n=56)$ and after $(n=55)$ the availability of NGS-based diagnostics at UKL in April 2016 (Figure 3A). While Interval 4 (initiation of first genetic diagnostics to initiation of final genetic diagnostics) dominates in the total diagnostic duration for individuals with symptom onset before the establishment of NGS, Interval 1 (first symptoms to initial diagnostics) emerges prominently for individuals with first symptoms after April 2016. The duration of the total diagnostic trajectory (Interval $1-5)$ significantly $(p<0.001$, Wilcox-Test) differed between individuals with first symptoms before and after 2016-04-01 (Figure 3B); the median interval length was 106.3 months (range: 21.7 - 201.5; SD: 50.2) for individuals with first symptoms before establishment of NGS, whereas it was shorter for individuals with first symptoms thereafter, with a median of 9.2 months (range: 0.6 - 43.3; SD: 12.1). This can be expected because recruitment of individuals in our study ended in August 2020. Therefore, the length of the total diagnostic time interval for individuals with first symptoms after the introduction of NGS is limited to a maximum of 4 years.

Dividing these subgroups based on their initial phenotype (NDD or epilepsy first), no significant differences between the phenotype groups emerged for individuals with initial symptoms before April 2016. Concerning individuals with first symptoms after 2016, those in 
medRxiv preprint doi: https://doi.org/10.1101/2021.07.23.21258974; this version posted July 24, 2021. The copyright holder for this preprint

the "epilepsy first" group received their molecular diagnosis significantly $(p \sim 0.002$, WilcoxTest) faster (3.9 months; range: 0.13 - 36.53; SD: 10.6) than individuals in the "NDD first" group (15.7 months; range: 0.62 - 43.3; SD: 12) (Figure 3C).

To compare the proportion of the total diagnostic interval pertaining to pediatrics with that of clinical genetics, we attributed Interval 1-3 (pediatrics) and 4-5 (genetics) to them. While only a relatively weak significant difference $(p \sim 0.03$, Wilcox-Test) was seen between the pediatrics and genetics proportions for individuals with first symptoms before April 2016, a highly significant difference $(\mathrm{p}<0.001$, Wilcox-Test) was observed between Interval 1-3 and 4-5 for individuals with first symptoms after 2016. For these individuals, the time allocated to pediatrics (193 days; range: 1 - 1115; SD: 326.4) was significantly longer than that attributed to genetics (54 days; range: 8 - 705; SD: 123.2) (Figure 3D, Supplemental Figure S3).

The duration of the total diagnostic pathway did not differ between individuals whose initial diagnosis took place at UKL and individuals whose initial diagnosis was performed at another medical institution in this cohort, in which all individuals received healthcare at UKL during the trajectory. (Supplemental Figure S4).

\section{Diagnostic procedures and costs}

Before receiving a genetically confirmed diagnosis, the individuals in our cohort underwent various diagnostic procedures (Figure 4A, Supplemental File $S 2^{26}$ ). All individuals received at least one genetic examination, 101 individuals (91\%) had at least one laboratory test other than metabolic testing and 86 individuals (77.5\%) received at least one cMRI. Other medical imaging was performed at least once in 78 (70.3\%) individuals, medical consults in 75 (67.6\%), EEG in 74 (66.7\%), metabolic diagnostics in 67 (60.4\%), lumbar puncture in 26 (23.4\%), electrophysiology in 26 (23.4\%), functional tests in 14 (12.6\%), ECG in 11 (9.9\%). From the overall cohort 95 individuals (85.6\%) were in inpatient care at UKL at least once (Supplemental Figure S5).

The diagnostic categories with the highest amounts of potentially non-required procedures are genetic diagnostics, metabolic diagnostics, and cMRI (Figure 4A). Of 407 genetic 
medRxiv preprint doi: https://doi.org/10.1101/2021.07.23.21258974; this version posted July 24, 2021. The copyright holder for this preprint

examinations performed overall, 296 (72.7\%) were categorized as potentially dispensable if an exome-wide analysis would have been performed initially instead. The different types of dispensable genetic diagnostics are mainly constituted by chromosomal analyses, arrays, single gene testing, fragile $X$ syndrome diagnostics and small custom gene panels (Figure $4 \mathrm{~A}$, top part). In total $129 \mathrm{cMRI}$ examinations were performed in this cohort, of which 36 (27.9\%) were categorized as not required. With one exception, all of those were performed under general anesthesia. Contrast agent was used in $18(50 \%)$ of dispensable imaging procedures. Of 349 metabolic examinations, 111 (31.8\%) were categorized as dispensable. Only a minority of procedures in the categories of laboratory tests other than metabolic tests, medical imaging except cMRI, electrophysiology, and EEG were classified as non-essential. All consults, ECG, functional tests, EEG examinations were classified as essential. We classified $21(7.3 \%)$ of a total of 288 inpatient stays performed as potentially dispensable. Among these, non-required hospitalizations had a median of 2 inpatient overnight stays (range: 1 - 7; SD: 1.9) and were shorter, with a significant $p$-value ( $p \sim 0.016$, Wilcox-Test), than hospitalizations classified as indispensable, with a median length of 4 nights (range: 0 731; SD: 46.7) (Supplemental Figure S6).

We calculated the costs for the three diagnostic categories with the largest number of nonrequired diagnostic procedures: genetic diagnostics, metabolic diagnostics, and cMRI. In our cohort, a total of $687,168.02 €$ was spent on genetic diagnostics. Thereof, $302,947.07 €$ (44.1\%) are associated with dispensable examinations. Of the $82,589.20 €$ spent on cMRI, $21,903.37 €(26.5 \%)$ were considered not required if the final genetic diagnosis would have been known and considered. From 35,980.43€ issued for metabolic examinations, a portion of $10,987.05 €(30.5 \%)$ was classified as not required (Figure 4B). Thus, genetic examinations show the highest potential for cost savings in our cohort with $302,947.07 €$ $(90.2 \%)$ out of $335,837.49 €$ in total potentially savable costs.

On average, the total potentially savable cost amounts to $3,025.56 €$ per individual in our study. This corresponds to an average of $2,729.25 €$ for genetic diagnostics, $197.33 €$ for CMRI examinations and $98.98 €$ for metabolic testing regarding potential cost savings. 
The amount of summed dispensable cost per individual does not correlate with the length of the diagnostic trajectory (Interval 1-5) for metabolic diagnostics and cMRI. In genetic diagnostics, a moderate positive correlation $(p<0.001$, Pearson correlation coefficient $=$ $\left.0.367, R^{2}=0.13\right)$ is observed between the amount of the summed costs of genetic testing per individual and the length of time needed to obtain a diagnosis (Figure 4C). 
medRxiv preprint doi: https://doi.org/10.1101/2021.07.23.21258974; this version posted July 24, 2021. The copyright holder for this preprint (which was not certified by peer review) is the author/funder, who has granted medRxiv a license to display the preprint in perpetuity.

It is made available under a CC-BY-NC 4.0 International license .

\section{DISCUSSION}

This retrospective cohort analysis emphasizes the importance of implementing ES as a first line test in the diagnostic pathway for individuals with NDD and/or epilepsy. NGS-based testing ended the hitherto inconclusive diagnostic pathway in all 111 individuals in our study. Therefore, the length of the diagnostic odyssey is significantly shorter in individuals with first symptoms onset after the availability of NGS than in individuals developing first symptoms before this cutoff time. It must be considered that our study included only individuals who received a final molecular diagnosis, and we can thus not assess individuals who had inconclusive NGS-based diagnostics. However, our design is a representative snapshot of the currently achievable diagnostic yield ( 31-53\%) using ES as a first-tier test ${ }^{33}$ in NDD/epilepsy.

Even before the broad availability of NGS in the clinical setting, genetic testing in this cohort was often initiated early by the treating pediatricians. However, the diagnostic odyssey was prolonged by the unavailability of genetic diagnostics covering the considerable heterogeneity observed in NDD and epilepsy (SysID database ${ }^{34}$ accessed on 2021-04-24 states 1,454 genes associated with NDD whereof 663 were associated with epilepsy). This caused a stepwise evaluation using karyotyping, microarrays and clinically suspected diagnoses. After the establishment of NGS, this phase receded, while the time interval before initiation of genetic diagnostics became critical for a fast diagnosis. Direct comparison of Interval 1-3 (pediatricians) and 4-5 (medical geneticists) before and after clinical availability of NGS demonstrates a remarkable reduction on the genetics side. This shows the accelerating impact of NGS-based methods on diagnostic time intervals. Thus, further potential for shortening the diagnostic process lies in the faster referral of individuals with NDD/ epilepsy to genetics testing.

Our data imply that individuals who first presented at other or smaller hospitals had no disadvantages in terms of elapsed time to molecular diagnosis. This achievement may be attributable to good cooperation between medical institutions or the pivotal and well-known role of our Center for Rare Diseases in our local area. 
medRxiv preprint doi: https://doi.org/10.1101/2021.07.23.21258974; this version posted July 24, 2021. The copyright holder for this preprint

Individuals with epilepsy received a quicker diagnosis in our cohort than those with NDD after establishment of clinical NGS. Thus, the decrease in diagnostic duration is more apparent in individuals with epilepsy. This might be explained by the assumption that pediatricians may be more sensitive to the possible genetic background of epilepsy. The potentially more acute clinical presentation of epileptic seizures could also have led to a more rapid initiation of genetic diagnostics. Furthermore, the renowned focus on epilepsy research in genetics at UKL may have contributed to this. It would be desirable if this could be increasingly established for NDD entities without epilepsy in the future.

Stark et al. ${ }^{35}$ and Tan et $\mathrm{al}^{36}$ examined the cost-effectiveness of NGS and also considered potential cost savings by omitting other traditional diagnostic procedures. These studies did however not consider whether these diagnostic interventions might nevertheless be indispensable in individual cases. Soden et al. ${ }^{27}$ analyzed potentially dispensable medical costs through rapid ES in NDDs, but included diagnostics that would have been performed even if the genetic diagnosis was known in their cost savings model. Therefore, our careful reassessment of each individual case, represents the first study to examine the extent of diagnostics that could retrospectively be replaced by early implementation of ES based on accepted criteria for diagnostics of NDD and epilepsy in a tertiary Center for Rare Diseases. The greatest potential for cost savings concerns prior genetic diagnostics in our study. Of the genetic tests performed, $72.7 \%$ were classified as potentially dispensable representing $90.2 \%$ of total savable costs. A reversal from classical genetic diagnostics to an exome first approach ${ }^{37}$ would thus have resulted in reduced diagnostic costs in our cohort. Particularly because ES is also increasingly suitable for the detection of CNVs (in our cohort $26 \mathrm{CNVs}$, including small and complex alternations like translocations, were identified through NGS), which provides an alternative to chromosomal microarrays. ${ }^{24,38-40}$ In case of inconclusive results in first tier ES, genetic examinations could be extended accordingly to entities possibly not covered, such as translocations, repeat disorders (fragile $\mathrm{X}$ syndrome) or mitochondrial disorders. 
medRxiv preprint doi: https://doi.org/10.1101/2021.07.23.21258974; this version posted July 24, 2021. The copyright holder for this preprint

The proportion of potentially dispensable metabolic (31.8\%) and cMRI examinations (27.9\%) is relevant in these categories. genetic testing can compete with, or even surpass, metabolic screening in terms of diagnostic yield. ${ }^{39,41}$ ES prior to the performance of these diagnostics should therefore explicitly be considered. Unlike other studies ${ }^{42}$ we did not classify all metabolic diagnostics as dispensable, because they are essential as confirmatory diagnostics and for decision making for therapies. Furthermore, metabolic testing currently still provides diagnostic results in critical situations faster than genetic testing. More rapid genetic results in the future could therefore replace additional metabolic examinations.

Our data suggest that the potential for diagnostic savings through ES lies primarily in genetic diagnostics itself, which is an effect of the granulated and step wise approach performed historically. Except for metabolic and cMRI examinations, there was little to no potential for savings in other diagnostic categories.

A comparison of the savable costs in our cohort with the results of other studies is limited, because of differences in study design and cohort selection. Tan et al. ${ }^{36}$ and Stark et al. ${ }^{35}$ prospectively designed different diagnostic pathways in the course of ES in an undiagnosed cohort and compared their estimated costs. Based on this, cost savings per additional diagnosis (inflated and currency converted values: 6,237.14€ and 1,561.58€) were determined. Soden et al. provide the mean costs of prior negative testing in non-acute individuals (inflated and currency converted value: 17,785.18€). Chung et $\mathrm{al}^{43}$, Monroe et al. ${ }^{42}$ and Vrijenhoek et al. ${ }^{22}$ calculated the cost savings per individual resulting from avoidable medical examinations due to early ES implementation (inflated and currency converted values: $110.63 € ; 3,277.66 €$ and $5,090.39 €)$. In some of these publications the costs of potentially unnecessary diagnostics even exceeded costs for ES. In our data, the cost of ES amounts to $3,461.45 €$ while the average cost savings by avoidable diagnostics is $3,025.56 €$ per individual. Thus, the average cost of potentially dispensable diagnostics almost reaches the cost level of an ES examination. The avoidable costs in this study are lower than in some previously publications. This may be an effect of our cautious evaluation of potentially dispensable diagnostics and our focus on solely direct diagnostic costs. Furthermore, 
medRxiv preprint doi: https://doi.org/10.1101/2021.07.23.21258974; this version posted July 24, 2021. The copyright holder for this preprint

previous studies report higher costs for individual parameters of metabolic diagnostics as well as for cMRI which could be explained by different pricing policies of health care systems in other countries.

Hospitalizations that we classified as potentially avoidable were shorter than indispensable inpatient stays. This can be explained by the solely diagnostic purpose of these not required hospitalizations, whereas required hospitalizations were mostly associated with complex therapies, emergency admissions, or a poor general condition of the individuals. While only $7.3 \%$ of inpatient stays (with a median of only 2 nights) were classified as dispensable, their potential omission could have been a major relief for affected families in individual cases. ${ }^{44}$ However, costs alone should not determine the course of action in the care of individuals affected by rare diseases. Early implementation of ES could not only reduce diagnostic costs and time, but also prevent exhausting or even risky procedures. In our study, more than a quarter of cMRI examinations were judged to be potentially dispensable and nearly all of these procedures were performed using anesthesia. The decision to put a child at risk ${ }^{45}$ for imaging with sedation and contrast agent could be influenced by the outcome of prioritized genetic testing since imaging results rarely lead to diagnosis in individuals with NDD. ${ }^{46} A$ quickly established molecular diagnosis can also affect therapy and further medical interventions $^{15,24,36,47}$, have an impact on family planning ${ }^{14,18}$, and contribute to the psychological well-being of the parents. ${ }^{16}$

Moreover, our study demonstrates the importance of reanalyzing and reevaluating exome data. $^{14,48}$ The reassessment of the SMAD4 variant initially reported as incidental finding in in Ind012 is of decisive clinical importance for the affected family who now do not have to partake invasive colonoscopies anymore. In addition, our reevaluation revealed one individual in which the previously reported genetic diagnosis could not sufficiently explain the observed phenotype because the associated phenotype was too mild. The formal downgrading of five variants is expected and an effect of continuous development and stricter interpretation of the ACMG criteria for variant classification. Nevertheless, we considered the five cases as resolved by the plausibility of these "hot VUS". Additional 
analyses in the future will facilitate a definitive assessment of these cases. Thus, reevaluating genetic findings in light of new guidelines and expanding genetic databases may yield new results. ${ }^{49}$

Limitations of this study include the relatively small cohort of 111 individuals, the lack of control group by focusing on solved cases only and the retrospective approach. Moreover, only a part of dispensable costs was determined, so the extent of these may potentially be higher. Some of the design choices in our study were imposed by the billing system and decentralized medical system in Germany.

Further studies on this topic should involve larger cohorts in a prospective setting. Collaboration among multiple rare disease centers and more complete collection of individuals' medical data across the boundaries of single medical institutions would benefit for this research aim. However, individuals with rare NDD and/or epilepsy entities will surely benefit from continued development and research into rapid and effective diagnostic pathways. Therefore, close and informed collaboration between different medical specialties, such as pediatrics and human genetics, is essential. Both early consideration of a genetic differential diagnosis and quick performance of ES can contribute to reduce diagnostic time, costs and exhausting medical procedures and enable a sooner reproductive choice in the families. 
medRxiv preprint doi: https://doi.org/10.1101/2021.07.23.21258974; this version posted July 24, 2021. The copyright holder for this preprint

(which was not certified by peer review) is the author/funder, who has granted medRxiv a license to display the preprint in perpetuity.

It is made available under a CC-BY-NC 4.0 International license .

\section{ACKNOWLEDGEMENTS}

We thank all involved families for participating in this study. We appreciate the support of the Institute of Human Genetics team members Julia Herrmann, Uwe Herrmann, Dr. Julia Hentschel, Anja Heinze and Marcel Frömming. This manuscript is part of a doctoral thesis of Julia Klau.

\section{CONFLICTS OF INTEREST}

The authors involved declare no conflicts of interest relevant to this study.

\section{FUNDING}

B.P. is supported by the Deutsche Forschungsgemeinschaft (DFG) through grant PO2366/21.

\section{AUTHORS' CONTRIBUTIONS}

J.R.L. and S.B. conceived the initial study concept. J.K. and S.B. collected, curated and classified the clinical data. R.A.J. and M.R. provided the genetic data and performed submission to public databases, with updates performed by J.K. after reevaluation. J.K., H.O., M.R. and B.P. reevaluated all variants according to current standards. J.K., S.B. and B.P. cleaned, standardized and analyzed all clinical and genetic data. J.K. and B.P. created Figures 1, 2, 3 and 4 and all Supplementary materials. J.K., J.R.L. and B.P. wrote and edited the manuscript. All authors reviewed and commented on the final draft of the manuscript.

\section{WEB RESOURCES}

AutoPVS1: http://autopvs1.genetics.bgi.com/

ClinGen CNV Interpretation Calculator: https://cnvcalc.clinicalgenome.org/cnvcalc/

ClinVar: https://www.ncbi.nlm.nih.gov/clinvar/

Decipher: https://www.deciphergenomics.org/

gnomAD: https://gnomad.broadinstitute.org/ 
Mutalyzer: https://mutalyzer.nl

Varsome: https://varsome.com/

\section{ABBREVIATIONS}

ACMG: American College of Medical Genetics

cMRI: cranial magnetic resonance imaging

CNV: copy number variant

DRGs: Diagnosis Related Groups

ECG: electrocardiogram

EEG: electroencephalogram

ES: exome sequencing

GOÄ: Gebührenordnung für Ärzte

MLPA: multiplex ligation-dependent probe amplification

NDD: neurodevelopmental disorder

NGS: Next Generation Sequencing

qPCR: quantitative polymerase chain reaction

RT-PCR: reverse transcription polymerase chain reaction

SD: standard deviation

SNV: single-nucleotide variant

UKL: Leipzig University Medical Center

VUS: variants of uncertain significance

\section{SUPPLEMENTARY FILES}

File S1: Supplementary notes with supplementary figures and tables.

File S2: Comprehensive tabular data describing relevant clinical cohort information (available ${ }^{26}$ on Zenodo).

File S3: Information on all variants identified in this cohort (available ${ }^{26}$ on Zenodo). 
medRxiv preprint doi: https://doi.org/10.1101/2021.07.23.21258974; this version posted July 24, 2021. The copyright holder for this preprint (which was not certified by peer review) is the author/funder, who has granted medRxiv a license to display the preprint in perpetuity. It is made available under a CC-BY-NC 4.0 International license .

\section{REFERENCES}

1. Kumar P., Radhakrishnan J., Chowdhary MA., Giampietro PF. Prevalence and Patterns of Presentation of Genetic Disorders in a Pediatric Emergency Department. Mayo Clinic Proceedings 2001;76(8):777-83. Doi: 10.4065/76.8.777.

2. Yoon PW. Contribution of Birth Defects and Genetic Diseases to Pediatric Hospitalizations: A Population-Based Study. Arch Pediatr Adolesc Med 1997;151(11):1096. Doi: 10.1001/archpedi.1997.02170480026004.

3. Gilissen C., Hehir-Kwa JY., Thung DT., van de Vorst M., van Bon BWM., Willemsen MH., et al. Genome sequencing identifies major causes of severe intellectual disability. Nature 2014;511(7509):344-7. Doi: 10.1038/nature13394.

4. Aaberg KM., Gunnes N., Bakken IJ., Lund Søraas C., Berntsen A., Magnus P., et al. Incidence and Prevalence of Childhood Epilepsy: A Nationwide Cohort Study. Pediatrics 2017;139(5):e20163908. Doi: 10.1542/peds.2016-3908.

5. Tavyev Asher YJ., Scaglia F. Molecular bases and clinical spectrum of early infantile epileptic encephalopathies. European Journal of Medical Genetics 2012;55(5):299-306. Doi: 10.1016/j.ejmg.2012.04.002.

6. Vorstman JAS., Ophoff RA. Genetic causes of developmental disorders: Current Opinion in Neurology 2013;26(2):128-36. Doi: 10.1097/WCO.0b013e32835f1a30.

7. Wang J., Lin Z-J., Liu L., Xu H-Q., Shi Y-W., Yi Y-H., et al. Epilepsy-associated genes. Seizure 2017;44:11-20. Doi: 10.1016/j.seizure.2016.11.030.

8. Hanly C., Shah H., Au PYB., Murias K. Description of neurodevelopmental phenotypes associated with 10 genetic neurodevelopmental disorders: A scoping review. Clinical Genetics 2021;99(3):335-46. Doi: 10.1111/cge.13882.

9. Carmichael N., Tsipis J., Windmueller G., Mandel L., Estrella E. "Is it Going to Hurt?": The Impact of the Diagnostic Odyssey on Children and Their Families. J Genet Counsel 2015;24(2):325-35. Doi: 10.1007/s10897-014-9773-9.

10. Gonzaludo N., Belmont JW., Gainullin VG., Taft RJ. Estimating the burden and economic impact of pediatric genetic disease. Genet Med 2019;21(8):1781-9. Doi: 10.1038/s41436-0180398-5.

11. McCandless SE., Brunger JW., Cassidy SB. The Burden of Genetic Disease on Inpatient Care in a Children's Hospital. The American Journal of Human Genetics 2004;74(1):121-7. Doi: 10.1086/381053.

12. Arim RG., Miller AR., Guèvremont A., Lach LM., Brehaut JC., Kohen DE. Children with neurodevelopmental disorders and disabilities: a population-based study of healthcare service utilization using administrative data. Dev Med Child Neurol 2017;59(12):1284-90. Doi: 10.1111/dmcn.13557.

13. Strzelczyk A., Reese JP., Dodel R., Hamer HM. Cost of Epilepsy: A Systematic Review. PharmacoEconomics 2008;26(6):463-76. Doi: 10.2165/00019053-200826060-00002.

14. Schofield D., Rynehart L., Shresthra R., White SM., Stark Z. Long-term economic impacts of exome sequencing for suspected monogenic disorders: diagnosis, management, and reproductive outcomes. Genet Med 2019;21(11):2586-93. Doi: 10.1038/s41436-019-0534-x.

15. Dixon-Salazar TJ., Silhavy JL., Udpa N., Schroth J., Bielas S., Schaffer AE., et al. Exome Sequencing Can Improve Diagnosis and Alter Patient Management. Science Translational Medicine 2012;4(138):138ra78-138ra78. Doi: 10.1126/scitranslmed.3003544.

16. Graungaard AH., Skov L. Why do we need a diagnosis? A qualitative study of parents? experiences, coping and needs, when the newborn child is severely disabled. Child Care Health Dev 2007;33(3):296-307. Doi: 10.1111/j.1365-2214.2006.00666.x.

17. Iglesias A., Anyane-Yeboa K., Wynn J., Wilson A., Truitt Cho M., Guzman E., et al. The usefulness of whole-exome sequencing in routine clinical practice. Genet Med 2014;16(12):92231. Doi: $10.1038 / \operatorname{gim} .2014 .58$. 
medRxiv preprint doi: https://doi.org/10.1101/2021.07.23.21258974; this version posted July 24, 2021. The copyright holder for this preprint (which was not certified by peer review) is the author/funder, who has granted medRxiv a license to display the preprint in perpetuity. It is made available under a CC-BY-NC 4.0 International license .

18. Srivastava S., Cohen JS., Vernon H., Barañano K., McClellan R., Jamal L., et al. Clinical whole exome sequencing in child neurology practice: WES in Child Neurology. Ann Neurol 2014;76(4):473-83. Doi: 10.1002/ana.24251.

19. Rump P., Jazayeri O., van Dijk-Bos KK., Johansson LF., van Essen AJ., Verheij JBGM., et al. Whole-exome sequencing is a powerful approach for establishing the etiological diagnosis in patients with intellectual disability and microcephaly. BMC Med Genomics 2015;9(1):7. Doi: 10.1186/s12920-016-0167-8.

20. Fernandez-Marmiesse A., Gouveia S., Couce ML. NGS Technologies as a Turning Point in Rare Disease Research , Diagnosis and Treatment. CMC 2018;25(3):404-32. Doi: 10.2174/0929867324666170718101946.

21. Demos M., Guella I., DeGuzman C., McKenzie MB., Buerki SE., Evans DM., et al. Diagnostic Yield and Treatment Impact of Targeted Exome Sequencing in Early-Onset Epilepsy. Front Neurol 2019;10:434. Doi: 10.3389/fneur.2019.00434.

22. Vrijenhoek T., Middelburg EM., Monroe GR., van Gassen KLI., Geenen JW., Hövels AM., et al. Whole-exome sequencing in intellectual disability; cost before and after a diagnosis. Eur J Hum Genet 2018;26(11):1566-71. Doi: 10.1038/s41431-018-0203-6.

23. Dillon OJ., Lunke S., Stark Z., Yeung A., Thorne N., Gaff C., et al. Exome sequencing has higher diagnostic yield compared to simulated disease-specific panels in children with suspected monogenic disorders. Eur J Hum Genet 2018;26(5):644-51. Doi: 10.1038/s41431-018-0099-1.

24. Zacher P., Mayer T., Brandhoff F., Bartolomaeus T., Le Duc D., Finzel M., et al. The genetic landscape of intellectual disability and epilepsy in adults and the elderly: a systematic genetic work-up of 150 individuals. Genet Med 2021. Doi: 10.1038/s41436-021-01153-6.

25. Lemke JR. High-Throughput Sequencing as First-Tier Diagnostics in Congenital and EarlyOnset Disorders. JAMA Pediatr 2017;171(9):833. Doi: 10.1001/jamapediatrics.2017.1970.

26. Klau, Julia., Popp, Bernt. Data files for manuscript "Exome first approach to reduce diagnostic costs and time - retrospective analysis of 111 individuals with rare neurodevelopmental disorders" 2021. Doi: 10.5281/ZENODO.5129075.

27. Soden SE., Saunders CJ., Willig LK., Farrow EG., Smith LD., Petrikin JE., et al. Effectiveness of exome and genome sequencing guided by acuity of illness for diagnosis of neurodevelopmental disorders. Science Translational Medicine 2014;6(265):265ra168-265ra168. Doi: 10.1126/scitranslmed. 3010076.

28. Schwarze K., Buchanan J., Taylor JC., Wordsworth S. Are whole-exome and whole-genome sequencing approaches cost-effective? A systematic review of the literature. Genet Med 2018;20(10):1122-30. Doi: 10.1038/gim.2017.247.

29. Richards S., Aziz N., Bale S., Bick D., Das S., Gastier-Foster J., et al. Standards and guidelines for the interpretation of sequence variants: a joint consensus recommendation of the American College of Medical Genetics and Genomics and the Association for Molecular Pathology. Genet Med 2015;17(5):405-23. Doi: 10.1038/gim.2015.30.

30. Witteveen JS., Willemsen MH., Dombroski TCD., van Bakel NHM., Nillesen WM., van Hulten JA., et al. Haploinsufficiency of MeCP2-interacting transcriptional co-repressor SIN3A causes mild intellectual disability by affecting the development of cortical integrity. Nat Genet 2016;48(8):877-87. Doi: 10.1038/ng.3619.

31. Patel RY., Shah N., Jackson AR., Ghosh R., Pawliczek P., Paithankar S., et al. ClinGen Pathogenicity Calculator: a configurable system for assessing pathogenicity of genetic variants. Genome Med 2017;9(1):3. Doi: 10.1186/s13073-016-0391-z.

32. Hussain T., Church JM. Juvenile polyposis syndrome. Clin Case Rep 2020;8(1):92-5. Doi: $10.1002 / \mathrm{ccr} 3.2616$.

33. Srivastava S., Love-Nichols JA., Dies KA., Ledbetter DH., Martin CL., Chung WK., et al. Metaanalysis and multidisciplinary consensus statement: exomesequencing is a first-tier clinical diagnostic test for individuals withneurodevelopmental disorders. Genet Med 2019;21(11):241321. Doi: 10.1038/s41436-019-0554-6. 
medRxiv preprint doi: https://doi.org/10.1101/2021.07.23.21258974; this version posted July 24, 2021. The copyright holder for this preprint (which was not certified by peer review) is the author/funder, who has granted medRxiv a license to display the preprint in perpetuity. It is made available under a CC-BY-NC 4.0 International license .

34. Kochinke K., Zweier C., Nijhof B., Fenckova M., Cizek P., Honti F., et al. Systematic Phenomics Analysis Deconvolutes Genes Mutated in Intellectual Disability into Biologically Coherent Modules. Am J Hum Genet 2016;98(1):149-64. Doi: 10.1016/j.ajhg.2015.11.024.

35. Stark Z., Schofield D., Alam K., Wilson W., Mupfeki N., Macciocca I., et al. Prospective comparison of the cost-effectiveness of clinical whole-exome sequencing with that of usual care overwhelmingly supports early use and reimbursement. Genet Med 2017;19(8):867-74. Doi: 10.1038/gim.2016.221.

36. Tan TY., Dillon OJ., Stark Z., Schofield D., Alam K., Shrestha R., et al. Diagnostic Impact and Cost-effectiveness of Whole-Exome Sequencing for Ambulant Children With Suspected Monogenic Conditions. JAMA Pediatr 2017;171(9):855. Doi: 10.1001/jamapediatrics.2017.1755.

37. Stark Z., Tan TY., Chong B., Brett GR., Yap P., Walsh M., et al. A prospective evaluation of whole-exome sequencing as a first-tier molecular test in infants with suspected monogenic disorders. Genet Med 2016;18(11):1090-6. Doi: 10.1038/gim.2016.1.

38. Quenez O., Cassinari K., Coutant S., Lecoquierre F., Le Guennec K., Rousseau S., et al. Detection of copy-number variations from NGS data using read depth information: a diagnostic performance evaluation. Eur J Hum Genet 2021;29(1):99-109. Doi: 10.1038/s41431-020-0672-2.

39. Berg AT., Coryell J., Saneto RP., Grinspan ZM., Alexander JJ., Kekis M., et al. Early-Life Epilepsies and the Emerging Role of Genetic Testing. JAMA Pediatr 2017;171(9):863. Doi: 10.1001/jamapediatrics.2017.1743.

40. Miyatake S., Koshimizu E., Fujita A., Fukai R., Imagawa E., Ohba C., et al. Detecting copynumber variations in whole-exome sequencing data using the eXome Hidden Markov Model: an 'exome-first' approach. J Hum Genet 2015;60(4):175-82. Doi: 10.1038/jhg.2014.124.

41. Yubero D., Brandi N., Ormazabal A., Garcia-Cazorla À., Pérez-Dueñas B., Campistol J., et al. Targeted Next Generation Sequencing in Patients with Inborn Errors of Metabolism. PLOS ONE 2016;11(5):e0156359. Doi: 10.1371/journal.pone.0156359.

42. Monroe GR., Frederix GW., Savelberg SMC., de Vries TI., Duran KJ., van der Smagt JJ., et al. Effectiveness of whole-exome sequencing and costs of the traditional diagnostic trajectory in children with intellectual disability. Genet Med 2016;18(9):949-56. Doi: 10.1038/gim.2015.200.

43. Chung CCY., Leung GKC., Mak CCY., Fung JLF., Lee M., Pei SLC., et al. Rapid whole-exome sequencing facilitates precision medicine in paediatric rare disease patients and reduces healthcare costs. The Lancet Regional Health - Western Pacific 2020;1:100001. Doi: 10.1016/j.lanwpc.2020.100001.

44. Seliner B., Latal B., Spirig R. When children with profound multiple disabilities are hospitalized: A cross-sectional survey of parental burden of care, quality of life of parents and their hospitalized children, and satisfaction with family-centered care: Parents of hospitalized children with disabilities. J Spec Pediatr Nurs 2016;21(3):147-57. Doi: 10.1111/jspn.12150.

45. Salerno S., Granata C., Trapenese M., Cannata V., Curione D., Rossi Espagnet MC., et al. Is MRI imaging in pediatric age totally safe? A critical reprisal. Radiol Med 2018;123(9):695-702. Doi: 10.1007/s11547-018-0896-1.

46. Murias K., Moir A., Myers KA., Liu I., Wei X-C. Systematic review of MRI findings in children with developmental delay or cognitive impairment. Brain and Development 2017;39(8):644-55. Doi: 10.1016/j.braindev.2017.04.006.

47. Willig LK., Petrikin JE., Smith LD., Saunders CJ., Thiffault I., Miller NA., et al. Whole-genome sequencing for identification of Mendelian disorders in critically ill infants: a retrospective analysis of diagnostic and clinical findings. The Lancet Respiratory Medicine 2015;3(5):377-87. Doi: 10.1016/S2213-2600(15)00139-3.

48. Fung JLF., Yu MHC., Huang S., Chung CCY., Chan MCY., Pajusalu S., et al. A three-year followup study evaluating clinical utility of exome sequencing and diagnostic potential of reanalysis. $N p j$ Genom Med 2020;5(1):37. Doi: 10.1038/s41525-020-00144-x.

49. Li J., Gao K., Yan H., Xiangwei W., Liu N., Wang T., et al. Reanalysis of whole exome sequencing data in patients with epilepsy and intellectual disability/mental retardation. Gene 2019;700:168-75. Doi: 10.1016/j.gene.2019.03.037. 
medRxiv preprint doi: https://doi.org/10.1101/2021.07.23.21258974; this version posted July 24, 2021. The copyright holder for this preprint (which was not certified by peer review) is the author/funder, who has granted medRxiv a license to display the preprint in perpetuity. It is made available under a CC-BY-NC 4.0 International license .

\section{TABLES AND FIGURES}

Figure 1 | Flowchart of participant recruitment and timeline.

(A) Workflow of the approach for selecting participating individuals for this study using the internal patient information system of the Institute of Human Genetics at the UKL. Further information on the excluded individual (Ind076) is provided in supplementary files.

(B) Schematic timeline showing the time points of the diagnostic trajectory researched from the patient's medical history and the resulting time intervals.

\section{Figure 2 | Individual and variant features.}

(A) Divergent plot representing the age distribution of individuals. The age determination refers to the date of final establishment of the human genetic diagnosis. The $y$-axis represents the age classes in years. The $x$-axis shows the number of associated individuals. (B) Stacked bar chart indicating the distribution of the phenotypes (epilepsy, NDD and the combination of both) in the 111 included individuals presented in percentages. (C) Stacked bar chart showing the distribution of all variant types found in the individuals including additional findings seen in no or low association with NDD or epilepsy presented in percentages $(n=127) . S N V=$ Single-nucleotide variant, Indel = Insertion/Deletion Polymorphism, Large CNV = Copy number variation whose alteration affects multiple genes, Small CNV = Copy number variation whose alteration affects a single gene and involves, for example, several

exons

(D) Stacked bar chart showing the inheritance patterns of those variants assigned to the respective phenotype of epilepsy or NDD $(n=111)$. homo $=$ homozygous, comphet $=$ compound heterozygous.

\section{Figure 3 | Impact of the establishment of NGS-based diagnostics on diagnostic time} intervals.

(A) Stacked bar plot showing the length of each diagnostic subinterval (Interval 1, 2, 3, 4 and 5) per individual, grouped by time of first symptom onset. The grouping was based on the establishment NGS-based human genetic diagnostics and labelled as before April 1, 2016 (Before Apr16) and after April 1, 2016 (After Apr16). Because of missing data in the medical histories of some individuals, we performed filtering for presentation purposes. Therefore, only individuals for which the duration of all diagnostic intervals could be calculated were included for this figure $(n=84)$. The color selection of the diagnostic intervals is based on the colors of the timeline in Figure 1B.

(B) Violin- and scatter-plot assembling the total diagnostic time interval (Interval 1 - 5, first symptoms to final human genetic diagnosis) grouped according to the time of onset of first symptoms. $(p<0.001$, Wilcox-Test $)$

(C) Violin- and scatter-plot assembling the total diagnostic time interval (Interval 1-5) grouped by phenotype according to the time of onset of first symptoms. Individuals with a combination 
medRxiv preprint doi: https://doi.org/10.1101/2021.07.23.21258974; this version posted July 24, 2021. The copyright holder for this preprint

(which was not certified by peer review) is the author/funder, who has granted medRxiv a license to display the preprint in perpetuity.

It is made available under a CC-BY-NC 4.0 International license .

of both phenotypes were assigned to the phenotype that occurred first in them, based on medical history research. (After Apr16: $p \sim 0.002$, Wilcox-Test)

(D) Violin- and scatter-plot assembling Interval 1-3 (first symptoms to initiation of first genetic diagnostics) and Interval 4-5 (initiation of first genetic diagnostics to final diagnosis) grouped by the onset time of first symptoms. (After Apr16: $p<0.001$, Wilcox-Test)

Figure 4 | Required and non-required diagnostic costs.

(A) Divergent plot illustrating the amount of required and not required diagnostics performed on the individuals. GEN = human genetic diagnostics, MET = metabolic laboratory testing, $\mathrm{CMRI}=$ cranial magnetic resonance imaging, Imaging = other medical imaging than cMRI, $E C G$ = electrocardiogram, EEG = electroencephalogram. The bar chart above categorizes the non-required genetic diagnostics. $\mathrm{CA}=$ Chromosome analysis, $\mathrm{SG}=$ Single Gene analysis, FISH = Fluorescence in situ hybridization, MLPA = Multiplex ligation-dependent probe amplification, Sub = Analysis of Subtelomeres, PWA = Prader-Willi syndrome and Angelman syndrome diagnostics, Single = Single Exome Diagnostics.

(B) Bar chart showing the respective costs grouped by top three diagnostic categories (with the highest amount of potential non-required diagnostics) and requirement. (C) Scatterplot showing the correlation of the respective unnecessary diagnostic costs with the length of the diagnostic odyssey (Interval 1-5), grouped by diagnostic category. The values for $R^{2}$ and the $p$-values are given in the plot. 
Table 1 | Information of the five individuals with "hot VUS" variants after reevaluation

\begin{tabular}{|c|c|c|c|c|c|c|c|}
\hline $\begin{array}{l}\text { Varia } \\
\text { nt ID }\end{array}$ & $\begin{array}{l}\text { Indivi } \\
\text { dual } \\
\text { ID }\end{array}$ & Gene & Variant & $\begin{array}{l}\text { Variant } \\
\text { classific } \\
\text { ation }\end{array}$ & $\begin{array}{l}\text { Classificat } \\
\text { ion rules }\end{array}$ & $\begin{array}{l}\text { Zygosit } \\
\text { y }\end{array}$ & Origin \\
\hline $\begin{array}{l}\text { SNV_ } \\
002\end{array}$ & Ind002 & $\begin{array}{l}\text { TUBB } \\
2 B\end{array}$ & $\begin{array}{l}\text { c. } 611 \mathrm{~A}>\mathrm{T}, \\
\text { p. }(\text { Asn204lle })\end{array}$ & VUS & $\begin{array}{l}\text { PM2_Supp } \\
\text { orting, } \\
\text { PP2_Supp } \\
\text { orting, } \\
\text { PP3_Supp } \\
\text { orting, } \\
\text { PP4_Supp } \\
\text { orting }\end{array}$ & $\begin{array}{l}\text { heterozy } \\
\text { gous }\end{array}$ & $\begin{array}{l}\text { matern } \\
\text { al }\end{array}$ \\
\hline $\begin{array}{l}\text { SNV_- } \\
022\end{array}$ & Ind019 & $\begin{array}{l}N P R L \\
3\end{array}$ & $\begin{array}{l}\text { c.434T>C, } \\
\text { p.(Leu145Pro) }\end{array}$ & VUS & $\begin{array}{l}\text { PS2_Moder } \\
\text { ate, } \\
\text { PM2_Supp } \\
\text { orting, } \\
\text { PP3_Supp } \\
\text { orting }\end{array}$ & $\begin{array}{l}\text { heterozy } \\
\text { gous }\end{array}$ & $\begin{array}{l}\text { de } \\
\text { novo } \\
\text { (confir } \\
\text { med) }\end{array}$ \\
\hline $\begin{array}{l}\text { SNV } \\
027\end{array}$ & Ind025 & $\begin{array}{l}\text { DYNC } \\
1 H 1\end{array}$ & $\begin{array}{l}\text { c. } 8945 G>A, \\
\text { p. }(\text { Arg2 } 2982 H i s)\end{array}$ & VUS & $\begin{array}{l}\text { PS2_Moder } \\
\text { ate, } \\
\text { PM2_Supp } \\
\text { orting, } \\
\text { PP2_Supp } \\
\text { orting, } \\
\text { PP3_Supp } \\
\text { orting }\end{array}$ & $\begin{array}{l}\text { heterozy } \\
\text { gous }\end{array}$ & $\begin{array}{l}\text { de } \\
\text { novo } \\
\text { (confir } \\
\text { med) }\end{array}$ \\
\hline $\begin{array}{l}\text { SNV } \\
067\end{array}$ & Ind069 & $\begin{array}{l}S C N 1 \\
A\end{array}$ & $\begin{array}{l}\text { c. } 4581+18 A>G \text {, } \\
\text { p.? }\end{array}$ & VUS & $\begin{array}{l}\text { PS2_Moder } \\
\text { ate, } \\
\text { PM2_Supp } \\
\text { orting, } \\
\text { PP3_Supp } \\
\text { orting }\end{array}$ & $\begin{array}{l}\text { heterozy } \\
\text { gous }\end{array}$ & $\begin{array}{l}\text { de } \\
\text { novo } \\
\text { (confir } \\
\text { med) }\end{array}$ \\
\hline $\begin{array}{l}\text { SNV } \\
073\end{array}$ & Ind077 & NBEA & $\begin{array}{l}\text { c. } 4662+1 G>C, \\
\text { p.Thr1519_Val } \\
\text { 1554del }\end{array}$ & VUS & $\begin{array}{l}\text { PVS1_Mod } \\
\text { erate, } \\
\text { PS2_Moder } \\
\text { ate, } \\
\text { PM2_Supp } \\
\text { orting }\end{array}$ & $\begin{array}{l}\text { heterozy } \\
\text { gous }\end{array}$ & $\begin{array}{l}\text { de } \\
\text { novo } \\
\text { (confir } \\
\text { med) }\end{array}$ \\
\hline
\end{tabular}


B Phenotypic distribution

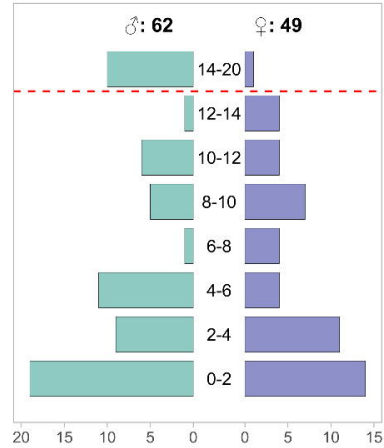

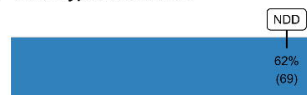

NDD + Epilepsy

C Variant type distribution

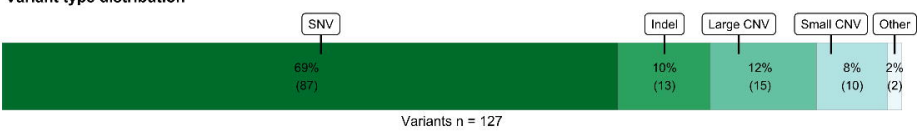

D Variant inheritance distribution

Variants $\mathrm{n}=111$

Variants $n=127$

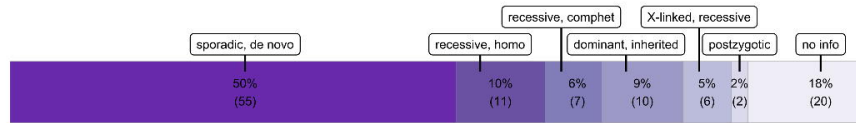

$\begin{array}{lllllllll}20 & 15 & 10 & 5 & 0 & 0 & 5 & 10 & 15\end{array}$ 
